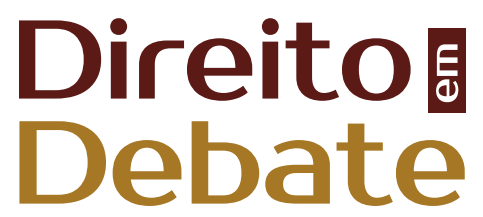

Revista do Departamento de Ciências Jurídicas e Sociais da Unijuí Editora Unijuí - Ano XXX - n. 56 - jul./dez. 2021 - ISSN 2176-6622

\title{
REFLEXÕES ACERCA DO IMPACTO DO CORONAVÍRUS SOBRE O DIREITO À SAÚDE E SUA TUTELA EM UMA PERSPECTIVA TRANSNACIONAL
}

\author{
http://dx.doi.org/10.21527/2176-6622.2021.56.10525
}

Recebido em: 8/4/2020

Modificações solicitadas em: 26/6/2020

Aceito em: 21/7/2020

Felipe Schmidt

Autor correspondente. Ministério Público do Estado de Santa Catarina - 13a Promotoria de Justiça da Comarca de Chapecó. Fórum da Comarca de Chapecó. Rua Augusta Muller Boner, n. 300 D - Passo dos Fortes. Chapecó/ SC, Brasil. CEP 89805-900. http://lattes.cnpq.br/0978563574294746. https://orcid.org/0000-0002-8798-9207.

fsmafra@gmail.com

\section{Elisandra Riffel Cimadon}

Universidade do Oeste de Santa Catarina. Joaçaba/SC, Brasil.

\section{RESUMO}

Este texto, desenvolvido sob o método indutivo e a partir de pesquisa doutrinária e legislativa, traz algumas reflexões introdutórias acerca do impacto do coronavírus sobre o direito à saúde e sua tutela em uma perspectiva transnacional. Inicialmente, faz breve descrição do coronavírus, abrangendo sua caracterização, origem e expansão. Em seguida, delineia as medidas jurídicas previstas na Lei n. 13.979, de 6 de fevereiro de 2020, para o enfrentamento do coronavírus no Brasil. Depois, passa ao exame dos perfis da tutela da saúde pública nos Estados Liberal, Social e Transnacional. Por fim, procede à abordagem de algumas das consequências jurídicas do combate ao coronavírus.

Palavras-chave: coronavírus; Covid-19; saúde pública; direito à saúde; governança; transnacionalidade.

\section{REFLECTIONS ABOUT THE IMPACT OF CORONAVIRUS ON THE RIGHT \\ TO HEALTH AND ITS PROTECTION IN A TRANSNATIONAL PERSPECTIVE}

\section{ABSTRACT}

This text, developed under Inductive Method and from doctrinal and legislative research, brings some introductory reflections on the impact of the coronavirus on the right to health and its protection in a transnational perspective. Initially, it briefly describes the coronavirus, covering its characterization, origin and expansion. Then, it outlines the legal measures provided for Act $n$. 13.979, of February 6, 2020, for the coronavirus confrontation in Brazil. Then, it goes on to examine the profiles of the tutelage of Public Health in Liberal, Social and Transnational State. Finally, it addresses some of the legal consequences of fighting coronavirus.

Keywords: Coronavirus; Covid-19; public health; right to health; governance; transnationality. 


\section{INTRODUÇÃO}

O presente texto traz algumas reflexões iniciais acerca do impacto do coronavírus sobre o direito à saúde e sua tutela em uma perspectiva transnacional. Trata-se de matéria atual, pois a transmissão do vírus vem crescendo exponencialmente em todo o mundo, e relevante, à vista da gravidade e alcance da moléstia por ele provocada, o que torna oportuna a análise ora levada a efeito.

O estudo principia com uma sucinta descrição do coronavírus, abrangendo sua caracterização, origem e expansão. Em seguida, são delineadas as medidas jurídicas previstas em lei para seu enfrentamento no Brasil. Depois, passa-se ao exame dos perfis da tutela da saúde pública nos Estados Liberal, Social e Transnacional. Por fim, procede-se à abordagem de algumas das possíveis consequências jurídicas transnacionais do combate ao coronavírus.

O trabalho foi desenvolvido à luz do Método Indutivo. Na primeira fase da pesquisa (decisão) especificou-se o referente: fazer considerações sobre o impacto do coronavírus sobre o direito à saúde e sua tutela no âmbito transnacional. Na segunda fase (investigação), passou-se à consulta a fontes de pesquisa doutrinária e legislativa sobre o tema. Na terceira fase (tratamento dos dados), correlacionaram-se os elementos apurados, pelo método cartesiano, e, na quarta fase (relatório), elaborou-se este artigo, com o desenvolvimento do referente anteriormente enunciado (PASOLD, 2018, p. 89-97).

\section{CORONAVÍRUS: BREVE CARACTERIZAÇÃO}

Segundo informações extraídas de site eletrônico do Ministério da Saúde do Brasil na rede mundial de computadores (BRASIL, 2020b), o coronavírus (Sars-Cov-2) é um vírus que causa doenças respiratórias, entre as quais a Covid-19, cuja expansão foi reconhecida como uma pandemia pela Organização Mundial de Saúde (OMS) (ESTADÃO, 2020).

Há consenso na comunidade científica de que, para a contenção e redução da velocidade de dispersão do Covid-19 ao redor do mundo, a medida mais eficaz é o distanciamento social, sendo necessário, ainda, o uso por todos de máscaras, luvas, álcool em gel ou $70 \%$ e outros meios para evitar a contaminação.

O coronavírus vem se disseminando por todo o mundo com rapidez, constando que teve surgimento na Ásia (China) (ESTADO DE MINAS, 2020), de onde se expandiu para a Europa (notadamente Itália e Espanha), indo então aos Estados Unidos e à América Latina, que tende a assumir a condição de epicentro de propagação do vírus e da moléstia, máxime em face das reconhecidas insuficiências e fragilidades da saúde pública prestada no continente e especificamente no Brasil.

Assim, ademais das características do próprio vírus e da moléstia antes sucintamente delineadas, é também diante desse contexto adverso de proteção e promoção da saúde pública no Brasil que se afigurou indispensável adotar medidas jurídicas excepcionais para o adequado enfrentamento do coronavírus no país.

\section{MEDIDAS JURÍDICAS PARA ENFRENTAMENTO DO CORONAVÍRUS NO BRASIL}

A competência legislativa para dispor sobre matéria afeta à saúde pública é concorrente, conforme prevê a Constituição da República (BRASIL, 1988) (artigo 24, XII), cabendo à União a edição de normas gerais (artigo 24, §1으), e aos Estados e Distrito Federal o exercício da competência suplementar (artigo 24, §2-). Aos municípios compete legislar sobre matérias de interesse local e também suplementar a legislação federal e estadual no que couber (artigo 30, I e II).

Nesse contexto, a fim de combater o coronavírus e atenuar seu impacto no Brasil, foi editada a Lei $\mathrm{n}$. 13.979 (BRASIL, 2020a), de 6 de fevereiro de 2020, que dispõe sobre medidas para enfrentamento da emergência em saúde pública relacionada ao coronavírus, abrangendo normas gerais aplicáveis à União, aos Estados, ao Distrito Federal e aos municípios, tratando-se, portanto, de lei nacional.

Tal lei consigna, logo em sua epígrafe e em seu artigo 1ํ, caput, que o problema de saúde pública a ser enfrentado como decorrência do referido vírus é de importância internacional, anotando, em seu artigo 1으, $\S 2 \circ$, que as medidas que estabelece objetivam a proteção de toda a coletividade. 
Essas disposições, embora apenas descrevam aspectos da realidade fática emergente, prestam-se para evidenciar, por exemplo, a imprescindibilidade da atuação do Ministério Público no trato da matéria, à vista do disposto no artigo 127, caput, da Constituição da República (BRASIL, 1988), que comete àquela instituição a defesa dos interesses sociais e individuais indisponíveis, bem assim do seu artigo 129, III, que lhe confia a tutela dos interesses difusos e coletivos, sem prejuízo, na forma de seu artigo 129, IX, da proteção aos interesses individuais homogêneos.

A referida lei estabelece ainda que para o enfrentamento da emergência de saúde pública decorrente do coronavírus as autoridades poderão adotar, cada qual nos limites de suas atribuições, medidas como isolamento (BRASIL, 2020a), ${ }^{1}$ quarentena (BRASIL, 2020a), ${ }^{2}$ determinação compulsória da realização de exames médicos, testes laboratoriais, coleta de amostras clínicas, vacinação e outras medidas profiláticas, tratamentos médicos específicos, estudo ou investigação epidemiológica, restrição excepcional e temporária de entrada e saída do país e locomoção interestadual ou intermunicipal, por rodovias, portos ou aeroportos, requisição de bens e serviços de pessoas naturais e jurídicas, com posterior pagamento de justa indenização, e autorização, também excepcional e temporária, para a importação de produtos sujeitos à vigilância sanitária sem registro na agência regulatória correspondente, desde que registrados por autoridade sanitária estrangeira e previstos em ato do Ministro de Estado da Saúde (artigo 3ㅇ) (BRASIL, 2020a).

Quanto à distinção entre isolamento e quarentena, figuras respectivamente previstas nos incisos I e II do artigo 3ㅇ da Lei n. 13.979, de 6 de fevereiro de 2020 (BRASIL, 2020a), e definidas nos incisos I e II do artigo 20 do mesmo texto legal, mas em geral usadas de modo indistinto, sem rigor técnico, há que se apontar que o isolamento se aplica a pessoas já doentes ou contaminadas (e a objetos afetados), ao passo que a quarentena destina-se a pessoas apenas suspeitas de contaminação (e a objetos igualmente suspeitos) em relação a outras que não estejam doentes. Ainda, o isolamento enseja separação de pessoas, ao passo que a quarentena implica a restrição de atividades ou a separação de pessoas, sendo, assim, de alcance mais amplo que aquela. Ambas as medidas, todavia, tendem a evitar a contaminação ou a propagação do coronavírus, aspecto no qual se assemelham.

Outrossim, como prevê o artigo 3ㅇ, §1으, da mesma lei (BRASIL, 2020a), as medidas nela elencadas somente poderão ser determinadas com base em evidências científicas e em análises sobre as informações estratégicas em saúde e deverão ser limitadas no tempo e no espaço ao mínimo indispensável à promoção e à preservação da saúde pública, disposição que tem o inequívoco escopo de garantir, sem prejuízo da eficácia das medidas eventualmente adotadas, o respeito aos direitos fundamentais.

Tanto é assim que a lei em comento assegura expressamente (artigo 3으, §2으) (BRASIL, 2020a) às pessoas afetadas pelas medidas que prevê (embora fosse isso dispensável, porque tal previsão dimana diretamente de atos normativos anteriores), os direitos de serem informadas permanentemente sobre seu estado de saúde e assistência à família (artigo 34 do Código de Ética Médica) (CFM, 2018) e de receberem tratamento gratuito (artigo 196 da Constituição da República) (BRASIL, 1988), bem assim o pleno respeito à dignidade, aos direitos humanos e às liberdades fundamentais (artigos. 1ㅇ a 5음 da Constituição da República) (BRASIL, 1988).

Ademais, toda pessoa deverá colaborar com as autoridades sanitárias na comunicação imediata de possíveis contatos com agentes infecciosos e circulação em áreas consideradas de contaminação pelo vírus (artigo 50) (BRASIL, 2020a). Quanto aos entes e órgãos da administração pública (federal, estadual, distrital ou municipal) e às pessoas jurídicas de Direito Privado, todos deverão compartilhar dados essenciais à identificação de pessoas infectadas ou com suspeita de infecção, com o único escopo de evitar a propagação do vírus (artigo 6o) (BRASIL, 2020a).

Por fim, importante consignar que a Lei n. 13.979, de 6 de fevereiro de 2020, vigorará enquanto perdurar o estado de emergência de saúde internacional decorrente do coronavírus (artigo 8ọ) (BRASIL, 2020a).

\footnotetext{
"[...] separação de pessoas doentes ou contaminadas, ou de bagagens, meios de transporte, mercadorias ou encomendas postais afetadas, de outros, de maneira a evitar a contaminação ou a propagação do coronavírus [...]".

2 " [...] restrição de atividades ou separação de pessoas suspeitas de contaminação das pessoas que não estejam doentes, ou de bagagens, contêineres, animais, meios de transporte ou mercadorias suspeitos de contaminação, de maneira a evitar a possível contaminação ou a propagação do coronavírus [...]".
} 
Em virtude dessa disposição, tal ato normativo consiste em lei temporária, assim compreendida aquela que é criada para regular fatos que tenham certo período de duração, ainda que não previamente definido, vigendo, assim, por lapso temporal limitado (CAPEZ, 2012, p. 84).

Os dispositivos legais restantes tratam, em suma, das atribuições das autoridades administrativas sanitárias para a adoção das medidas em comento, das licitações para aquisição de bens e serviços destinados ao enfrentamento da emergência de saúde pública em tela, excepcionando as normas gerais de regência da matéria, e de outras determinações de natureza administrativa, aspectos que fogem ao objeto deste artigo e que por isso não serão nele abordados.

À vista dessa disciplina legislativa de âmbito nacional, aos Estados, ao Distrito Federal e aos municípios, como apontado, também é lícito dispor sobre medidas de combate ao coronavírus, cada qual no exercício de sua competência legislativa própria, conforme antes exposto, devendo observar os ditames do regramento geral da matéria, fixado pela Lei n. 13.979, de 6 de fevereiro de 2020. Podem esses entes da Federação, contudo, legislar de forma distinta do que fez a União, desde que prevejam medidas mais restritivas de enfrentamento do vírus, mas não para flexibilizar ou relativizar seu combate, sob pena de inconstitucionalidade por violação do princípio federativo, ademais da ineficácia geral da confrontação à pandemia.

Nesse contexto, cumpre registrar que o Supremo Tribunal Federal decidiu sobre a matéria de maneira diversa, conforme segue:

[...] Ao abrir a divergência, o ministro Alexandre de Moraes assinalou que a União tem o papel central de coordenação na pandemia, nos moldes estabelecidos pela Constituição Federal, especialmente em relação ao Sistema Único de Saúde (SUS), mas não detém o monopólio das medidas. Ele considera que a administração federal deve respeitar o pacto federativo e não tem exclusividade para determinar medidas de âmbito local, por desconhecimento das necessidades e das peculiaridades das diversas regiões. Segundo ele, a União pode, por exemplo, determinar medidas para impedir o desabastecimento ou acelerar a chegada de medicamentos em determinadas regiões. Neste caso, prevalece o interesse nacional. Por outro lado, o ministro considera inviável que a União impeça os Estados de criarem barreiras sanitárias, caso haja interesse local. "Se houver medida de interesse geral, a União pode atuar, mas não pode excluir os Estados e os municípios" afirmou. "Ninguém tem o monopólio no combate à pandemia". De acordo com o ministro, Estados e municípios não podem ficar sujeitos à autorização da Anvisa ou de outros órgãos federais para tomar medidas de isolamento ou de quarentena. Eles devem seguir as recomendações de especialistas, mas não é possível que estejam vinculados a um órgão da União. Esse entendimento foi seguido pelos ministros Luiz Fux, Cármen Lúcia, Ricardo Lewandowski e Gilmar Mendes [...] (STF..., 2020).

Desse modo, a adoção, pelo presente estudo, de compreensão diferente daquela adotada pela Corte Suprema quanto à matéria, deveu-se ao entendimento de que a adstrição dos Estados, Distrito Federal e municípios às disposições de gênese da União tem potencial para, em tese, prejudicar o combate à Covid-19.

A realidade brasileira, porém, em um contexto de pandemia torna-se ainda mais emergencial quando se vê a situação adversa em que, como decorrência do coronavírus, se encontram países mais desenvolvidos econômica e socialmente. Por tal motivo faz-se importante trazer alguns apontamentos acerca dos perfis da tutela da saúde pública nos Estados Liberal, Social e Transnacional.

\section{PERFIS DA TUTELA DA SAÚDE PÚBLICA NOS ESTADOS LIBERAL, SOCIAL E TRANSNACIONAL}

Saúde pública é categoria de conceito controvertido (AITH, 2007, p. 50), podendo se referir a uma realidade epidemiológica, ao estado geral de saúde de uma população, à atividade estatal de administração da saúde, um campo de conhecimento ou uma área de atuação profissional (AITH, 2007, p. 50-51). Para os fins deste estudo, a saúde pública será compreendida como um bem jurídico primário, de natureza difusa, ${ }^{3}$ a ser tutelado conjuntamente pelo Estado e pela coletividade.

\footnotetext{
O conceito legal de direito, interesse ou bem difuso consta do artigo 81, parágrafo único, I, da Lei n. 8.078/90, vindo assim enunciado: "[...] os transindividuais, de natureza indivisível, de que sejam titulares pessoas indeterminadas e ligadas por circunstâncias de fato".
} 
Entre os temas historicamente atrelados ao domínio da saúde pública figura o das epidemias, "pois são fenômenos sanitários coletivos que demandam e justificam a intervenção dos governantes e de seus técnicos, visando à proteção da saúde coletiva" (AITH, 2007, p. 57-58).

Assim, a saúde pública e sua tutela assumiram diversos perfis no curso das transformações pelas quais passou o Estado ao longo do tempo.

À época do Estado Liberal, e mesmo antes dele, não havia a previsão de um dever geral de efetiva tutela, pelo Estado, da saúde, cabendo a cada pessoa, família ou grupo adotar seus próprios cuidados quanto a si e a seus membros, à vista dos recursos de que dispusesse para tanto. A atenção mais organizada à saúde de outrem era então apenas caritativa, benemerente, a cargo em especial de organizações de natureza religiosa (Santas Casas da Misericórdia e Hospitais de Caridade, por exemplo) (CEDENHO, 2012, p. 23).

Já no período do Estado Social, notadamente como decorrência das duas guerras mundiais havidas no século 20 e das maiores demandas por serviços de saúde delas decorrentes, o poder público assumiu para si, em cada Estado, o dever de promover e assegurar, de modo geral, a saúde da coletividade (CEDENHO, 2012, p. 31).

As Constituições passaram então a prever um direito fundamental de todos à saúde, ao qual corresponde o dever estatal de prestá-lo, a ser satisfeito, à luz do que prevê, por exemplo, no Brasil, a Constituição vigente, a partir de políticas públicas sociais e econômicas tendentes à redução do risco de doença e de outros agravos e ao acesso universal e igualitário às ações e serviços para sua promoção, proteção e recuperação (artigo 196) (BRASIL, 1988). Tais ações e serviços de saúde, considerados de relevância pública (artigo 197) (BRASIL, 1988), integram uma rede regionalizada e hierarquizada num sistema único, pautado pelas diretrizes de descentralização, atendimento integral e participação da comunidade (artigo 198) (BRASIL, 1988).

Tal dever estatal de tutela do direito fundamental à saúde, todavia, até porque previsto na ordem jurídica de cada país, que vige nos limites do respectivo território, é efetivado em âmbito nacional apenas.

Ocorre que, na atualidade, como a ameaça à saúde por vezes tem caráter global, e não só mais nacional ou local, mostra-se necessária também uma tutela transnacional da saúde pública, a cargo não apenas do Estado, mas de organismos internacionais e da coletividade. Essa necessidade é reforçada pela percepção de que "a desigualdade dos diferentes países na promoção da saúde e no controle das doenças, especialmente as transmissíveis, constitui um perigo comum" (DALLARI; NUNES JÚNIOR, 2010, p. 9).

O Estado, por si só, máxime no mundo globalizado (ADOLFO, 2001, p. 54), ${ }^{4}$ embora ainda pretenda fazê-lo, não mais consegue controlar os riscos civilizatórios (ORSELI; ARAÚJO, 2012, p. 2.662) ou encontrar soluções eficazes para problemas por vezes transfronteiriços que se lhe apresentam, entre os quais os afetos à saúde pública, como está a demonstrar o coronavírus.

Diante de tal panorama, no qual o problema a ser enfrentado (coronavírus) não adere a dado território, mas é transnacional, "apenas a cooperação interestatal seria eficiente" (ORSELI; ARAÚJO, 2012, p. 2.662) para combatê-lo, devendo, pois, o Estado igualmente prescindir da dimensão territorial (deflagrando uma atuação transnacional) para enfrentá-lo.

Cabível, assim, para a adequada tutela da saúde pública em tempos de globalização, uma atuação não de governo (vale dizer, meramente estatal), mas de governança, entendida como "a capacidade governativa em sentido amplo, na qual o Estado torna-se mais flexível, capaz de descentralizar funções, transferir responsabilidades e alargar o universo dos atores participantes" (MORAIS; NASCIMENTO, 2010, p. 33). E isso em âmbito transnacional, à vista dos contornos do coronavírus.

Correto está Ferrajoli (2020) quando afirma que "o coronavírus não conhece fronteiras. Ele já se espaIhou para quase todo o mundo e certamente por toda a Europa. É uma emergência global que exigiria uma resposta global", e que "[...] diante de emergências dessa natureza, sejam adotadas medidas eficazes e, sobretudo, homogêneas [...]".

\footnotetext{
4 "Globalização refere-se a processos atuantes em escala global, que ultrapassam fronteiras nacionais, integrando e conectando comunidades e organizações em novas combinações de espaço-tempo [...]"
} 
Muito embora, no entanto, se busque uniformidade nas decisões e medidas a serem adotadas para o enfrentamento da doença em âmbito mundial, as consequências jurídicas transacionais são de toda a ordem e refazem algo que se buscou superar com a globalização: a noção de fronteiras territoriais. Essa noção agora afrouxada de fronteiras territoriais abre a reflexão para as consequências jurídicas transnacionais do combate ao coronavírus.

\section{CONSEQUÊNCIAS JURÍDICAS TRANSNACIONAIS DO COMBATE AO CORONAVÍRUS}

No contexto delineado atualmente, parece haver, como decorrência da necessidade de conter a rápida expansão do coronavírus, um ressurgimento ou resgate da noção de fronteiras territoriais entre os Estados, que até então parecia ter se afrouxado como decorrência da globalização.

Com efeito, a relativização dos limites territoriais correlata à globalização impulsionou o livre trânsito de pessoas e de bens entre os Estados e os continentes, mas foi justamente esse fluxo mais facilitado e ágil de pessoas que ensejou a rápida disseminação do coronavírus por praticamente todo o globo.

À vista disso, apressaram-se os governos em reerguer os entraves ao livre fluxo de pessoas por suas fronteiras, sejam estas terrestres, marítimas ou aéreas, a fim de conter o coronavírus. Ao agir desse modo para preservar a saúde de seus nacionais, todavia, acabaram por afetar, o que é inevitável, outros direitos igualmente fundamentais (a liberdade de ir e vir, por exemplo).

Ademais, a necessidade de gestão global de determinadas questões e dos eventuais problemas que lhes são correlatos (saúde pública e meio ambiente, por exemplo) obrigou os Estados a coordenarem também suas políticas (ROTH, 2015, p. 18). Desse modo, hoje cada Estado considera a situação externa (no caso sob exame, quanto ao coronavírus) para elaborar seu Direito interno, mudando, assim, a própria base de legitimação de sua produção normativa (ROTH, 2015, p. 18), que não deve atender mais apenas aos interesses dos seus cidadãos (eleitores), mas aos dos de outros países e continentes e mesmo a toda a humanidade, que pode(rão) (rá) ser, direta ou indiretamente, afetad(os)(a) por decisões adotadas em lugar(es) distante(s).

Ainda quanto à produção do Direito, da análise das medidas de enfrentamento ao coronavírus adotadas no Brasil vê-se que se altera também, para além de sua base de legitimação, o próprio perfil do Direito de gênese estatal.

Com efeito, o Direto estatal intenta recobrar a força que lhe vem sendo tolhida por conta da globalização, que ensejou sua coexistência com a normatização jurídica emanada de outros agentes, notadamente econômicos (em especial as empresas transnacionais) (GROSSI, 2010, p. 76), pretendendo assim voltar a ocupar a posição de centro de tomada das decisões políticas fundamentais da sociedade (ADOLFO, 2001, p. 75) (ao menos em sede de adoção de medidas eficazes de combate ao coronavírus). É o que se vê, pontualmente, no embate entre a determinação governamental de isolamento e quarentena (artigo 2ㅇ, I e II, c/c artigo 3ㅇ, I e II, ambos da Lei n. 13.979, de 6 de fevereiro de 2020) (BRASIL, 2020a) e a oposição de parcela do empresariado nacional à sua observância, como foi amplamente divulgado pela imprensa (UOL, 2020; JORNAL DE BRASÍLIA, 2020).

Outrossim, o direito estatal passa a assumir conteúdo também de incitação, além da pura e simples proibição (direito negativo) que o caracteriza, buscando influenciar os diversos atores sociais a tomar decisões conformes às metas perseguidas (ROTH, 2015, p. 24). Nessa linha, o Direito estatal, no que tange, à vista dos limites deste estudo, ao combate ao coronavírus, visa a estimular os cidadãos a permanecer no interior de suas residências, bem assim a suspender ou a restringir dadas atividades, como as que importem aglomeração de pessoas.

Nesse contexto, há ainda que se reconhecer que apenas a intervenção do Estado não basta mais para a adequada tutela da saúde pública, mesmo se considerada em âmbito meramente nacional. Assim, em tempos de quarentena por conta do coronavírus (artigo 20, II, c/c artigo 3ㅇ, II, da Lei n. 13.979, de 6 de fevereiro de 2020) afigura-se necessário redescobrir solidariedades tradicionais (ROTH, 2015, p. 17) e horizontais preexistentes (SANTOS, 2001, p. 85), mas que se haviam afrouxado ou perdido com o decorrer do tempo (vínculos com a família, os vizinhos e outros atores sociais).

Além disso, as figuras do risco e da prevenção ganham maior relevância. 
O risco é concebido por Ulrich Beck como uma situação de ameaça global (BECK, 2013, p. 26), que está por toda parte e atinge a todas as pessoas indistintamente, não se podendo opor uma "classe dos afetados" a uma "classe dos não afetados", mas apenas a uma "classe dos ainda não afetados" (47), sendo certo que "[...] agora existe uma espécie de destino associado à ameaça na civilização avançada" (p. 49). Assim, trata-se de figura em tudo correlata ao coronavírus.

Quanto à prevenção, esta tem primazia sobre a reparação ou a compensação na tutela dos interesses coletivos (artigo 5ำ XXXV, da Constituição da República (BRASIL, 1988), artigo 84 da Lei n. 8.078/90) (BRASIL, 1990), como é o caso daqueles afetos à saúde pública, tendo em vista a necessidade de evitar a efetiva produção dos danos, cuja recuperação, por vezes, se afigura difícil e/ou dispendiosa (veja-se o expressivo montante de recursos destinados ao tratamento de pacientes do coronavírus ao redor do mundo), quando não impossível (basta pensar nos milhares de pessoas que foram a óbito como decorrência da moléstia).

A combinação desses aspectos talvez possa conduzir a uma desaceleração da globalização, assertiva que, todavia, consiste apenas em uma hipótese ainda remota, cuja comprovação depende do desenrolar dos fatos. De todo modo, já se evidenciou que o resultado eficiente do enfrentamento do coronavírus deve resultar da conjunção dos esforços de todos, e não mais apenas do Estado.

Nesse amplo contexto exsurge a fraternidade como princípio do universalismo político, pois enseja "discussões sobre as relações e sobre os vínculos de solidariedade comunitária" (SILVA; BRANDÃO, 2015, p. 102), que acabam por expandir a cidadania para além dos limites territoriais do Estado (p. 104). Ademais, "a fraternidade estabelece uma dinâmica de reciprocidade na ação entre pessoas humanas" (SILVA; BRANDÃO, 2015, p. 110), o que se afigura relevante para a eficiente superação da pandemia de coronavírus.

Por fim, conforme Ferrajoli (2020), há uma grande diferença das catástrofes que acometeram a humanidade no passado: "[...] o caráter global das catástrofes atuais, que afetam todo o mundo, a humanidade inteira, sem diferença de nacionalidade, de cultura, de língua, de religião e até de condições econômicas e políticas". Assim, a cidadania, agora considerada em âmbito transnacional e pautada pela fraternidade, deve se organizar para a defesa do interesse público primário afeto à saúde, titularizado indistintamente por toda a coletividade ao redor do globo.

\section{CONSIDERAÇÕES FINAIS}

Ao fim do presente estudo, percebe-se que o coronavírus (Sars-Cov-2) é um vírus que causa doenças respiratórias, entre as quais a Covid-19, cuja expansão, que vem se dando por todo o mundo e com rapidez, foi reconhecida como uma pandemia pela Organização Mundial de Saúde (OMS), havendo risco de a América Latina assumir a condição de epicentro de propagação do vírus e da moléstia, principalmente em razão das reconhecidas insuficiências e fragilidades da saúde PÚBLICA prestada no continente e especificamente no Brasil.

À vista dessas circunstâncias, foi editada no país a Lei n. 13.979, de 6 de fevereiro de 2020 (BRASIL, 2020a), que dispõe sobre medidas para enfrentamento da emergência em saúde pública relacionada ao coronavírus, tratando-se de lei nacional e de vigência temporária.

Tal lei preceitua que, para o enfrentamento da emergência de saúde pública decorrente do coronavírus, as autoridades poderão adotar, cada qual nos limites de suas atribuições, medidas como isolamento e quarentena, entre outras que acarretam restrição à plena liberdade dos cidadãos, com base em evidências científicas e em análises sobre as informações estratégicas em saúde, e que deverão ser limitadas no tempo e no espaço ao mínimo indispensável à promoção e à preservação da saúde pública, de modo a preservar os direitos fundamentais.

A realidade da saúde pública brasileira em um contexto de pandemia torna-se ainda mais emergencial quando se vê a situação adversa em que, como decorrência do coronavírus, se encontram os sistemas de saúde pública de países mais desenvolvidos econômica e socialmente, uma vez que a moléstia está devastando todo o planeta.

A saúde pública e sua tutela assumiram diversos perfis no curso das transformações por que passou o Estado ao longo do tempo: à época do Estado Liberal, não havia a previsão de um dever geral de tutela, pelo Estado, da saúde, cabendo a cada pessoa, família ou grupo adotar seus próprios cuidados quanto a si e a seus 
membros, sendo a atenção mais organizada à saúde de outrem então apenas caritativa, benemerente, a cargo em especial de organizações de natureza religiosa; ao tempo do Estado Social, o poder público assumiu para si o dever de promover e assegurar, de modo geral, a saúde da coletividade, e as Constituições passaram a prever um direito fundamental de todos à saúde, a ser exigido e efetivado nos limites territoriais de cada Estado; na atualidade, como a ameaça à saúde por vezes tem caráter global, e não só mais nacional ou local, mostra-se necessária também uma tutela transnacional da saúde pública, a cargo não apenas do Estado, mas de organismos internacionais e da coletividade, pois aquele, sozinho, em especial em tempo de pandemia, não ostenta mais condições de tutelar integralmente tal interesse, à vista de seus contornos globais.

Nesse contexto transnacional parece haver, como decorrência da necessidade de conter a rápida expansão do coronavírus, um ressurgimento ou resgate da noção de fronteiras territoriais entre os Estados, que tinha se afrouxado como decorrência da globalização.

Com efeito, a relativização dos limites territoriais correlata à globalização impulsionou o livre trânsito de pessoas e de bens entre os Estados e os continentes, mas foi justamente esse fluxo mais facilitado e ágil de pessoas que ensejou a rápida disseminação do coronavírus por praticamente todo o globo.

Surge daí a necessidade de gestão global de determinadas questões e dos eventuais problemas que lhes são correlatos, o que obrigou os Estados a coordenarem também suas políticas de saúde. Ademais, o Direito Estatal passou a assumir conteúdo também de incitação, além da pura e simples proibição (direito negativo) que o caracterizava, buscando influenciar os diversos atores sociais a tomar decisões conformes às metas perseguidas.

Outrossim, afigura-se necessário redescobrir solidariedades tradicionais e horizontais preexistentes, mas que se haviam afrouxado ou perdido com o decorrer do tempo (vínculos com a família, os vizinhos e outros atores sociais). A cidadania, princípio constitucional fundamental, tornou-se palavra de ordem nesse novo contexto global. A fraternidade, princípio do universalismo político, vem expandir a cidadania para além dos limites territoriais do Estado e mostrar a relevância da reciprocidade de ação das pessoas entre si e dos governos. Com efeito, o coronavírus faz relembrar que não há distinção entre as pessoas em sua essência, que todos somos iguais e que todos temos direitos, mas também deveres, para conosco mesmos e para com os outros.

Isso posto, embora haja um resgate da noção de fronteira territorial, que parecia ter sido esquecida, as noções de cidadania e de fraternidade assumem importância muito maior, pois direcionam toda a humanidade no sentido de um único objetivo: preservar a saúde e a vida acima de qualquer outro interesse.

\section{REFERÊNCIAS}

ADOLFO, Luiz Gonzaga Silva. Globalização e Estado contemporâneo. São Paulo: Memória Jurídica, 2001.

AITH, Fernando. Curso de Direito Sanitário. A proteção do direito à saúde no Brasil. São Paulo: Quartier Latin, 2007.

BECK, Ulrich. Sociedade de risco. Rumo a uma outra modernidade. 2. ed. Tradução Sebastião Nascimento. São Paulo: Editora 34, 2013. (Título original: Risikogesellschaft: auf dem Weg in eine andere Moderne).

BRASIL. Constituição da República Federativa do Brasil. Brasília, DF: Senado Federal, 1988. Disponível em: http://www.planalto.gov.br/ccivil_03/constituicao/constituicaocompilado.htm. Acesso em: 13 jun. 2020.

BRASIL. Lei n. 8.078, de 11 de setembro de 1990. Dispõe sobre a proteção do consumidor e dá outras providências. Brasília, DF: Senado Federal, 1990. Disponível em: http://www.planalto.gov.br/ccivil_03/leis/L8078compilado.htm. Acesso em: 13 jun. 2020.

BRASIL. Lei n. 13.979, de 6 de fevereiro de 2020. Dispõe sobre as medidas para enfrentamento da emergência de saúde pública de importância internacional decorrente do coronavírus responsável pelo surto de 2019. Brasília, DF: Senado Federal, 2020a. Disponível em: http://www.planalto.gov.br/ccivil_03/_ato2019-2022/2020/lei/L13979.htm. Acesso em: 13 jun. 2020.

BRASIL. Ministério da Saúde. coronavírus - Covid-19. 2020b. Disponível em: https://coronavirus.saude.gov.br/. Acesso em: 13 jun. 2020.

CAPEZ, Fernando. Curso de Direito Penal. Volume I. Parte Geral. (Arts. 1o a 120). 16. ed. São Paulo: Saraiva, 2012.

CEDENHO, Antonio Carlos. Diretrizes constitucionais da assistência social. São Paulo: Verbatim, 2012.

CFM. Conselho Federal de Medicina. Resolução CFM n. 2.217, de 27 de setembro de 2018. Código de Ética Médica. Disponível em: https://portal.cfm.org.br/images/PDF/cem2019.pdf. Acesso em: 13 jun. 2020. 


\section{Direito自

DALLARI, Sueli Gandolfi; NUNES JUNIOR, Vidal Serrano. Direito sanitário. São Paulo: Verbatim, 2010.

ESTADÃO. OMS declara pandemia de novo coronavírus. 2020. Disponível em: https://saude.estadao.com.br/noticias/ geral,oms-declara-pandemia-de-novo-coronavirus-mais-de-118-mil-casos-foram-registrados,70003228725. Acesso em: 6 abr. 2020.

ESTADO DE MINAS. Cronologia da expansão do novo coronavírus descoberto na China. Seção Internacional, 7 fev. 2020. Disponível em: https://www.em.com.br/app/noticia/internacional/2020/02/07/interna_internacional,1120153/cronologiada-expansao-do-novo-coronavirus-descoberto-na-china.shtml. Acesso em: 6 abr. 2020.

FERRAJOLI, Luigi. O vírus põe a globalização de joelhos. 2020. Disponível em: http://www.ihu.unisinos.br/78-noticias/597204o-virus-poe-a-globalizacao-de-joelhos-artigo-de-luigi-ferrajoli. Acesso em: 13 jun. 2020.

GROSSI, Paolo. O direito entre poder e ordenamento. Apresentação e tradução de Arno Dal Ri Junior. Belo Horizonte: Del Rey, 2010. (Título original: II diritto tra potere e ordenamento).

JORNAL DE BRASÍLIA. Empresários e entidades planejam manifestações contra isolamento no Paraná. 2020. Disponível em: https://jornaldebrasilia.com.br/brasil/empresarios-e-entidades-planejam-manifestacoes-contra-isolamento-no-parana/. Acesso em: 6 abr. 2020.

MORAIS, José Luis Bolzan de; NASCIMENTO, Valéria Ribas do. Constitucionalismo e cidadania. Por uma jurisdição constitucional democrática. Porto Alegre: Livraria do Advogado, 2010 (Coleção Estado e Constituição, 10).

ORSELLI, Helena Maria Zanetti de Azeredo; ARAUJO, Roseana Maria Alencar de. Estados transnacionais: aspectos destacados da proposta de Ulrich Beck. Revista Eletrônica Direito e Política, Itajaí, v. 7, n. 3, set./dez. 2012.

PASOLD, Cesar Luiz. Metodologia da pesquisa jurídica: teoria e prática. 14. ed. Florianópolis: Empório Modara, 2018. ROTH, André-Noël. O Direito em crise: fim do Estado Moderno. Tradução Margaret Cristina Toba e Márcia Maria Lopes Romero. In: FARIA, José Eduardo (org.). Direito e globalização econômica. Implicações e perspectivas. São Paulo: Malheiros, 2015.

SANTOS, Milton. Por uma outra globalização. Do pensamento único à consciência universal. 5. ed. Rio de Janeiro: Record, 2001.

SILVA, Ildete Regina do Vale da; BRANDÃO, Paulo de Tarso. Constituição e fraternidade. O valor normativo do preâmbulo da Constituição. Curitiba: Juruá, 2015.

STF. Supremo Tribunal Federal. Notícias. Quinta-feira, 30 abr. 2020. Disponível em: http://www.stf.jus.br/portal/cms/ verNoticiaDetalhe.asp?idConteudo=442500. Acesso em: 28 maio 2020.

UOL. Madero, Havan, Giraffas: empresários criticam medidas de combate à pandemia. 2020. Disponível em: https:// economia.uol.com.br/noticias/redacao/2020/03/24/empresarios-coronavirus-o-que-dizem-criticas.htm. Acesso em: 6 abr. 2020. 